\title{
ENSINO REMOTO EM TEMPOS DE PANDEMIA: A PERCEPÇÃO DOS PROFESSORES DE UMA ESCOLA PÚBLICA DO INTERIOR DE MATO GROSSO
}

\author{
Alisson Henrique Araújo de Souza ${ }^{1}$
}

RESUMO: A pandemia da COVID-ı9 fez com que instituições de ensino do mundo inteiro adotassem a modalidade de ensino remoto emergencial. Os professores utilizaram de plataforma digital para ministrar as aulas, mas para que isso ocorresse tiveram que passar por capacitações para remodelarem seus modelos de educação presencial para adotarem a educação digital. O objetivo deste artigo foi analisar qual a percepção dos professores da escola pública sobre o ensino remoto em tempos de pandemia. Para tal, a estratégia utilizada foi de caráter exploratório descritivo, através de um estudo de campo com coleta de informações através de um questionário semiestruturado, e disponibilizado para os respondentes via plataforma digital, GoogleForms. Para os professores, a falta de capacitação tornou a adaptação ao ensino remoto difícil, porém, a maior dificuldade apresentada está relacionada ao aluno, manter o foco e a participação ativa dos alunos durante as aulas virtuais, além de fazer com que estes realizem as atividades propostas e cumpram o cronograma.

Palavras-chave: Professores. Ensino remoto. Pandemia. Covid-rg.

ABSTRACT: The COVID-r9 pandemic caused educational institutions around the world to adopt the emergency remote teaching modality. The teachers used a digital platform to apply the classes, but for this to happen they had to undergo training to remodel their face-to-face education models to adopt digital education. The purpose of this article was to analyze the perception of public-school teachers about remote teaching in times of a pandemic. To this end, the strategy used was exploratory and descriptive, through a field study with information collection through a semi-structured questionnaire, and made available to respondents via the digital platform, GoogleForms. For teachers, the lack of training made adapting to remote teaching difficult, however, the biggest difficulty presented is related to the student, maintaining the focus and active participation of students during virtual classes, in addition to making them carry out the activities proposals and stick to the schedule.

Keywords: Teachers. Remote teaching. Pandemic. Covid-19.

\footnotetext{
${ }^{\text {I }}$ Servidor Público Estadual na Secretaria do Estado de Mato Grosso - SEDUC-MT. Pós Graduado em Gestão Escolar e Educação Digital pela FAVENI. Graduado em Administração pela Universidade do Estado de MatoGrosso - UNEMAT. Graduado em Agronomia pela Universidade do Estado de Mato Grosso - UNEMAT.
} 


\section{INTRODUÇÃO}

$\mathrm{O}$ ano de 2020 foi marcado pela pandemia de Covid-ı9, fato este que causou mudanças na rotina de todo o planeta. O setor educacional foi um dos mais afetados, as atividades pedagógicas presenciais foram suspensas e os órgãos responsáveis determinaram o retorno das atividades de modo remoto (RONDINI; PEDRO; DUARTE, 2020). Diante deste cenário escolar, inúmeros países discutiram internamente possibilidades de atendimento escolar em situações de excepcionalidade (ARRUDA, 2020).

Devido a pandemia da COVID-ı, as instituições de ensino, no mundo todo, adotaram a modalidade de ensino remoto emergencial, para evitar a perda do ano letivo (RONDINI; PEDRO; DUARTE, 2020). A área da educação teve as aulas presenciais suspensas no Estado de Mato Grosso em março de 2020, sendo então elaborado um plano para retomada das atividades escolares que ocorreu em agosto do mesmo ano. A medida adotada pela Secretaria de Educação do Estado foram aulas online para os alunos que tinham acesso a rede de internet e material apostilado para os alunos que não tinham como se conectar de forma online com os professores.

Para Arruda (2020) o isolamento social promoveu transformações econômicas severas imediatas, com a parada obrigatória de inúmeros setores, modificou nossa relação com a arte, devido à ausência do compartilhamento presencial de experiências de fruição e, no caso da educação, promove desconstruções sob a forma como o ensino e a aprendizagem são vistos socialmente.

Os professores utilizaram de plataforma digital para ministrar as aulas, mas para que isso ocorresse tiveram que passar por capacitações para remodelarem seus modelos de educação presencial para adotarem a educação digital. No interior do Mato Grosso, em uma escola publica estadual, os professores utilizaram a plataforma Microsoft Teams e Whatsapp para apresentarem as aulas e manter a comunicação com os estudantes. Arruda (2020) afirma que a educação remota é um princípio importante para manter o vínculo entre estudantes, professores e demais profissionais da Educação. Oliveira; Silva; Silva (2020) diz que a sala de aula, já não pode ser entendida apenas como espaço físico, com alunos e carteiras enfileiradas 
ou em círculo.

Todavia, mesmo com o ensino remoto, as relações entre professores e alunos mudaram, e muitos alunos não apresentaram o mesmo rendimento como em aulas presenciais, e na visão dos professores, as medidas adotadas não suprem a necessidade de uma relação mais próxima entre professor e aluno da educação básica para a construção do conhecimento. O objetivo deste artigo foi analisar qual a percepção dos professores da escola pública sobre o ensino remoto em tempos de pandemia, traçando o perfil destes professores e em sua visão, qual o efeito desta modalidade excepcional de ensino terá sobre o aprendizado dos alunos. A relevância deste trabalho se dá através do entendimento dos efeitos futuros das medidas adotadas no ensino remoto na relação ensino aprendizagem.

Para atingir os objetivos, foi realizada uma pesquisa de campo utilizando questionário semiestruturado com questões abertas e fechadas, aplicado aos professores via plataforma GoogleForms. Os dados foram analisados qualitativamente, e apresentados em forma textual, descrevendo de forma sucinta as percepções dos professores sobre o tema.

\section{DESENVOLVIMENTO}

\section{I.I Fundamentação Teórica}

\section{I.I.I Professores e o Ensino remoto}

Moreira et al (2020) diz que uma sala de aula online não é um repositório de conteúdos digitais, é um espaço ativo e dinâmico onde os estudantes recebem informações sobre as atividades online que devem realizar, dentro e fora da plataforma, individualmente ou em grupo, exatamente como num ambiente de sala de aula física. $O$ mesmo autor ainda complementa explicando que a mudanças na sociedade ocorreram de maneira significativa devido a evolução das tecnologias e das redes de comunicação, o que, de certa forma impulsiona o surgimento de paradigmas que antes não existiam, novos cenários de ensino aprendizagem e processos de comunicação educacional.

Cada instituição, cada curso e cada docente precisou criar um "novo modelo" de ensino-aprendizagem em formato digital. Contudo, apesar de alguns professores 
terem competências relacionadas ao uso de $\mathrm{TICs}^{2}$, e até mesmo estarem confortáveis aplicando ensino híbrido em suas instituições de ensino, essa não é uma realidade para a grande maioria. O papel do professor, nesse novo contexto de ensino aprendizagem, precisou ser revisto e atualizado, visando manter a qualidade da educação, mesmo nesse atual cenário catastrófico. Da mesma maneira, instituição e estudantes também precisaram rever seus papéis nesse processo (SUGITA et al, 2020, p.39).

Nesse processo a educação se vê na urgência de reinventar-se para acompanhar essas transformações, e, ao mesmo tempo, precisa pensar numa nova concepção da ação pedagógica, de sala de aula (OLIVEIRA; SILVA; SILVA, 2020). A reinvenção diária é necessária para os professores para dar seguimento às atividades pedagógicas. $O$ período, embora desafiador possa ser visto como promissor, no contexto educacional, ampliando o uso das tecnologias digitais no processo de ensino-aprendizagem, em todos os níveis de ensino (RONDINI; PEDRO; DUARTE, 2020).

Para Oliveira; Silva; Silva (2020) o entendimento é que ao se considerar as dimensões epistemológicas, política, sociocultural e histórica das tecnologias digitais, estas podem se constituir para os professores, como uma possibilidade de produção de outros sentidos para a prática pedagógica, de modo a desconstruir um processo de significação estabilizado pelo fazer docente meramente técnico. Já para Sugita et al (2020) os princípios de um processo pedagógico efetivo não devem ser alterados, pois o que mudou é o modelo de disponibilização do conhecimento. Porém, de acordo com Moreira et al (2020) ninguém, nem mesmo os professores que já adotavam ambientes online nas suas práticas, imaginava que seria necessária uma mudança tão rápida e emergencial, de forma quase obrigatória, devido à expansão do Covid-ı.

Com isso os professores foram obrigados a se adequarem para a realidade do ensino remoto, transferindo e transpondo metodologias e práticas pedagógicas típicas dos territórios físicos de aprendizagem, naquilo que tem sido designado por ensino remoto de emergência. Além dos professores, gestores e coordenadores tiveram que adaptar conteúdos curriculares, dinâmicas de sala e até avaliações para dar continuidade as aulas. No entanto, na maioria dos casos, estas tecnologias foram e estão sendo utilizadas numa perspectiva meramente instrumental, reduzindo as

${ }^{2}$ Conjunto de recursos tecnológicos integrados entre si, que proporcionam, por meio das funções de hardware, software e telecomunicações, a automação e comunicação dos processos de negócios, da pesquisa científica e de ensino e aprendizagem. 
metodologias e as práticas a um ensino apenas transmissivo (MOREIRA et al, 2020; OLIVEIRA; SILVA; SILVA, 2020).

Para se produzirem atividades online bem estruturadas, se deve tirar o maior aproveitamento possível dos recursos existentes e das tecnologias digitais. As e-atividades permitem uma aprendizagem online ativa, participativa, individual ou em grupo (MOREIRA et al, 2020). Portanto, conforme Oliveira; Silva; Silva, (2020) o desafio do professor, é observar as mudanças ocorridas para compreendê-las, no âmbito de seu trabalho pedagógico, para que possa ressignificá-lo e atualizá-lo. Isso exige um tempo mais longo para formação dos envolvidos no processo, com preparação de infraestrutura tecnológica que vise à aprendizagem.

De acordo com Moreira et al (2020), a educação em rede é um processo que requer o envolvimento profundo de todos os participantes, seja para definir quais os caminhos da aprendizagem e seus objetivos além dos processos de inovação e criação do novo

conhecimento. É, pois, urgente e necessário transitar deste ensino remoto de emergência, importante numa primeira fase, para uma educação digital em rede de qualidade (MOREIRA et $\mathrm{al}, 2020$ ).

Sendo a educação digital em rede, um processo que se caracteriza pela conectividade, rapidez, fluidez, apropriação de recursos abertos é necessário desencadear processos educativos destinados a melhorar e a desenvolver a qualidade profissional dos professores que, claramente, neste momento, foram pegos de surpresa (MOREIRA et al, 2020).

\subsubsection{Tecnologias digitais na educação remota}

O ensino remoto emergencial difere da modalidade de Educação a Distância (EAD), pois a EAD conta com recursos e uma equipe multiprofissional preparada para ofertar os conteúdos e atividades pedagógicas, por meio de diferentes mídias em plataformas on-line (RONDINI; PEDRO; DUARTE, 2020). Para Arruda (2020) as inúmeras soluções tecnológicas tornaram-se as principais referências potencializadoras de iniciativas voltadas para a manutenção da conexão educacional e se apresentam com razoável viabilidade 
para possibilitar uma política pública de manutenção das portas escolares abertas, ainda que de forma virtual, sobretudo com a ampliação do acesso a equipamentos como computadores, tablets e smartphones e conexão à internet.

Em contrapartida, para Rondini; Pedro; Duarte (2020), o objetivo do ensino remoto não é estruturar um ecossistema educacional robusto, mas ofertar acesso temporário aos conteúdos curriculares que seriam desenvolvidos presencialmente. Assim, em decorrência da pandemia, optou-se pelo ensino remoto emergencial como principal alternativa de instituições educacionais.

Conforme Arruda (2020) a escola, por ser um espaço de formação das novas gerações para a integração social, cultural e econômica, não pode prescindir de saberes e práticas vinculadas ao uso e apropriação de tecnologias digitais. Caso contrário, a tecnologia torna-se um paliativo para atender situações emergenciais.

Arruda (2020) em sua análise sobre as medidas adotadas pela educação em vários países, salienta que a maioria desses procurou incluir políticas para minimizar problemas de acesso. Além da disponibilização online, os materiais podem ser também impressos para alunos sem acesso à Internet. Esse caminho foi testado pela Espanha, por exemplo, que encontrou desafios como a falta de universalização de acesso, bem como a falta de proximidade dos docentes com a apropriação pedagógica das TICs.

As tecnologias em si não promovem a produção do conhecimento, nem o aprendizado, pois é preciso uma reconfiguração das práticas pedagógicas para a potencializar a interação entre os sujeitos envolvidos no processo de ensino e aprendizagem (OLIVEIRA; SILVA; SILVA, 2020). Recursos digitais e tecnologias audiovisuais são muito importantes nesta equação, pois sua utilização em contextos virtuais de aprendizagem, permitem congregar todas as vertentes da literacia, podendo, pois, revelar-se uma opção bastante válida e eficaz (MOREIRA et al, 2020).

Todavia, muitos desafios como, a manutenção do link de acesso contínuo aos conteúdos, são encontrados nessa estratégia, além da dificuldade em manter os alunos atentos e concentrados bem como a dificuldade dos docentes em realizar leituras corporais e 
manter um ambiente mais interativo, tornando a educação online desafiadora (ARRUDA, 2020).

As salas de aula virtuais de comunicação assíncrona, normalmente conhecidas por "fóruns" são fundamentais e respondem à essência da educação digital em rede, já que não requerem uma confluência do professor e de seus estudantes no espaço e no tempo, proporcionando a flexibilidade que caracteriza este modelo educativo (MOREIRA et al, 2020). Porém, foi necessário mudanças de forma abrupta no sistema educacional, de sorte que, de um dia para o outro, os professores foram obrigados a adaptar suas aulas e colocar seus conteúdos em plataformas on-line com o emprego das Tecnologias Digitais da Informação e Comunicação (TDIC), sem preparação para isso, ou com preparação superficial, também em caráter emergencial (RONDINI; PEDRO; DUARTE, 2020).

$\mathrm{Se}$ as tecnologias digitais nas escolas forem direcionadas para fins pedagógicos que contribuam com o desenvolvimento intelectual e cultural dos alunos, contribuirão impreterivelmente numa nova forma de concepção de currículo, de organização escolar, de tempo e espaço, redimensionando o olhar de todos os envolvidos no processo educativo. Cabe ressaltar que o essencial não é a tecnologia em si, mas sim a necessidade de reconfigurar, de ampliar e criar práticas pedagógicas que potencializem a interação entre os envolvidos nos processos de ensino e aprendizagem (OLIVEIRA; SILVA; SILVA, 2020).

\subsection{Procedimentos Metodológicos}

Trata-se de uma pesquisa com abordagem qualitativa. Qualitativa devido a apresentar como recorte principal, o estudo de campo que, de acordo com Gil (2008) pressupõe certa flexibilidade na coleta de dados. Também devido a amostra ser não probabilística e buscar abordar também a percepção dos sujeitos.

Para atingir os objetivos desta pesquisa, a estratégia utilizada foi de caráter exploratório descritivo. A pesquisa de natureza exploratória fez-se necessária para proporcionar maior familiaridade do pesquisador com o tema proposto, permitindo acesso ao 
maior número de informações possíveis. Assim, trata-se do primeiro passo para qualquer estudo científico (ANDRADE, 2003; GIL, 2008).

Na pesquisa descritiva, "os fatos são observados, registrados, analisados, classificados e interpretados, sem que o pesquisador interfira neles”, utilizando-se de técnicas padronizadas para a coleta dos dados (ANDRADE, 2003).

Para tanto, foi realizado um estudo de campo com coleta de informações através de um questionário semiestruturado, e disponibilizado para os respondentes via plataforma digital, GoogleForms. Também foi realizada uma pesquisa bibliográfica sobre o tema estudado. Segundo Vergara (2004) a pesquisa bibliográfica tem o intuito de fundamentar as informações coletadas, dando valor científico ao estudo.

Após a coleta dos dados, o pesquisador passou para a fase de apresentação, análise e interpretação dos mesmos. Assim, os dados apresentados, em forma textual, foram analisados qualitativamente por meio de análise estatística descritiva das respostas organizadas de forma percentual. Quanto aos dados qualitativos em relação a percepção dos professores em relação ao ensino remoto, sua análise e interpretação seguiu a sequência sugerida por Miles e Huberman (1994), redução dos dados; apresentação; e conclusão/verificação.

\section{I.3 Resultados e Discussão}

Ao todo foram 18 professores respondentes, dentre eles, somente dois do sexo masculino, quanto a idade destes, 2 possuem menos de 30 anos de idade, ou seja, são os chamados nativos digitais, seis tem entre 30 e 40 anos, seis entre 40 e 50 anos e 4 possuem idade superior a 50 anos. Em relação ao tempo de docência, 22\% possuem menos de io anos de prática docente, $28 \%$ entre io e is anos de prática, $17 \%$ entre 15 e 20 anos e $33 \%$ mais de 20 anos de experiencia docente. Com isso temos professores com muitos anos de prática docente, todos com especialização em suas áreas de ensino, exceto um que já possui mestrado acadêmico e que já passaram por diversas experiencias em sala de aula, porém apenas dois destes se sentiam preparados para o ensino digital. Carvalho (2018) confirma esses dados 
mostrando em sua pesquisa que os professores da educação básica, são em sua grande maioria mulheres, com idade média de 4I anos. Mais de 30\% possuem especialização.

Referente ao uso das tecnologias, para que o ensino remoto fosse adotado, 14 dos 18 professores passaram por formação adequada para tal modalidade de ensino, mas mesmo com a formação ainda sentiram que faltou maior tempo para adaptação das práticas pedagógicas. Para 60\% dos professores, a falta de capacitação tornou a adaptação ao ensino remoto difícil. Oliveira; Silva; Silva (2020) aponta que a formação pedagógica ou ações formativas que orientem os professores a transitarem de um modelo tradicional para uma abordagem integradora das TICs como mediadoras da aprendizagem é um desafio à educação.

Moreira (2020) afirma que apesar das vantagens que representam, as tecnologias digitais carecem de uma quase permanente formação, porque nessa área, a inovação acontece a todo o momento, o que por vezes proporciona mudanças significativas nas práticas dos professores. Os professores abordaram que não conseguiram se adequar ao uso das tecnologias, recursos audiovisuais, ferramentas para criação e edição de vídeos. Problemas com os computadores foram apontados por $65 \%$ dos professores, que destacam que possuem máquinas velhas e com tecnologia atrasada para atender a demanda exigida durante o ensino remoto.

Sobretudo, a maior dificuldade apresentada está relacionada ao aluno, em manter o foco e a participação ativa dos alunos durante as aulas virtuais, além de fazer com que estes realizem as atividades propostas e cumpram o cronograma. O professor dezoito ${ }^{3}$ disse "as maiores dificuldades foram de fazer os alunos participar e internet de qualidade para os interessados poderem participar das aulas online". Para Sugita et al (2020) independente do instrumento, o estudante precisa ser engajado no processo e a tecnologia, apesar do fascínio causado inicialmente, não é suficiente para manter esse interesse e dedicação.

Quando questionados se o ensino remoto adotado para o período de pandemia da Covid-19 supriu as necessidades formativas, 61\% afirmaram que parcialmente e 39\%

\footnotetext{
${ }^{3}$ Para não expor a identidade do respondente iremos apresentar o número do questionário que o mesmo utilizou.
} 
afirmaram que não, que esta modalidade de ensino não supre a necessidade dos alunos em formação, sobretudo na educação básica. Em relação a avaliação do modelo de ensino, 6ı\% avaliam como regular o uso do ensino digital adotado, 33\% avaliam como péssimo e 5\% como bom.

A percepção dos professores em relação ao ensino remoto mostra que estes não ficaram satisfeitos com os resultados apresentados ao fim do ano letivo. Para o professor cinco, "faltou clareza, definição, capacitação eficaz, qualidade”. Todavia, a educação por meio digital foi utilizada para que não houvesse a perca total do ano letivo, entretanto, as dificuldades não deixaram que este fosse um meio capaz de atender todos os alunos. O professor seis disse "seria um método excepcional se todos alunos conseguissem acesso. Pois devido a fatores como condições financeiras muitos alunos (não tem a palavra "não" aqui?) tem internet em casa, deixando apenas em um sistema limitado de ensino" Sobretudo, em sua pesquisa com I70 professores, Rondini; Pedro; Duarte (2020) identificaram que, apesar das dificuldades em transpor o ensino presencial para a modalidade remota e na utilização das TICs, os docentes apontam o quanto o momento pandêmico é desafiador e enriquecedor, para a sua prática, fazendo aflorar o processo de "reinvenção" docente.

\section{CONCLUSÃO}

$\mathrm{O}$ ano de 2020 foi desafiador para todos os setores, sobretudo a educação. Com as escolas fechadas, a comunidade escolar, professores e alunos tiveram que adequar suas relações de ensino aprendizagem para a conclusão do ano letivo.

O ensino remoto, modalidade adotada pelo Estado de Mato Grosso, com aulas virtuais utilizando plataformas digitais foi um grande constituiu, um grande desafio para professores se adaptarem a nova forma de ministrar suas aulas, repassar conteúdo e gerar conhecimento. Muitos destes tiveram inúmeros problemas com as TIC, pois além da falta de formação para esta prática didática, não possuíam recursos disponíveis como computadores com capacidade de processamento e internet de qualidade para apresentação das aulas virtuais.

A maior dificuldade apontada pelos professores foi em manter a atenção dos alunos e fazer com que estes permanecessem em aula, além de cumprirem as atividades e o 
cronograma proposto. De acordo com os professores, a modalidade de ensino remoto foi insuficiente para satisfazer as necessidades formativas dos alunos, alem de ser exclusiva, pois muitos alunos não tinham acesso às aulas.

\section{REFERÊNCIAS}

ANDRADE, M. M. Introdução a Metodologia do Trabalho Científico: elaboração de trabalhos na graduação. 6a ed. São Paulo: Atlas, 2003.

ARRUDA. E. P. Educação Remota Emergencial: elementos para políticas públicas na educação brasileira em tempos de Covid-19. EmRede, v. 7, n. I, p. 257-275. ISSN 2359-6082

CARVALHO, M. R. V. Perfil do professor da Educação Básica. INEP. Brasília, 2018. 67 p.

Miles, M. B.; HUBERMAN, A. M. Qualitative Data Analysis. 2 ed. Sage Publications, 1994 .

MOREIRA, J. A. M.; HENRIQUES, S.; BARROS, D. Transitando de um ensino remoto emergencial para uma educação digital em rede, em tempos de pandemia. Dialogia, São Paulo, n. 34, p. 351-364, jan./abr. 2020. DOI: https://doi.org/I0.5585/Dialogia.N34.17123

OLIVEIRA, S. S.; SILVA, O. S. F.; SILVA, M. J. O. Educar Na Incerteza e na Urgência: Implicações do Ensino Remoto ao Fazer Docente e a Reinvenção da Sala de Aula. Interfaces Científicas, Aracaju, V.ıo, N.I, p. 25 - 40, Número Temático - 2020. DOI: 10.17564/2316-3828. 2020, vio, ni, p 25-40.

RONDINI, C. A.; PEDRO, K. M.; DUARTE, C. S. Pandemia da Covid-rg e o Ensino Remoto Emergencial: Mudanças na Prática Pedagógica. Interfaces Científicas, Aracaju, V.ıo, N.I, p. 4I - 57, Número Temático - 2020. DOI: 10.17564/2316-3828. 2020, vio, ni, p4I-57.

SUGITA, D. M.; et al. (Novas) Competências Docentes Para O Ensino Remoto. v. 2 n. 2, 2020. In: Anais - 39ํㅗ Seminário De Atualização De Práticas Docentes. Disponível em: http://anais.unievangelica.edu.br/index.php/praticasdocentes/article/view/5795. Acesso em 07 de março de 2021.

VERGARA, S. C. Projetos e relatórios de pesquisa em Administração. São Paulo: Atlas, 2004. 